\title{
ALDOSTERONE ANTAGONISM BY 17-SPIROLACTOSTEROIDS
}

\author{
J. D. H. Slater, M.A., M.B., M.R.C.P. \\ Medical Registrar, Postgraduate Medical School, London, W. 2
}

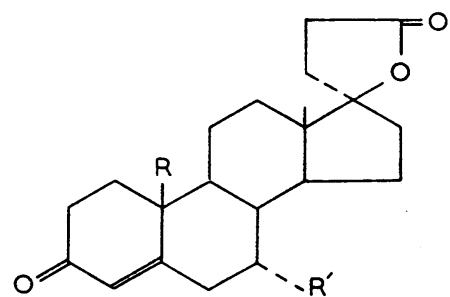

17-SPIROLACTOSTEROIDS

$\begin{array}{lll}\text { in SC } 5233 & R=\mathrm{CH}_{3} ; R^{\prime}=\mathrm{H} \\ \text { in SC } 8109 & R=H \quad ; R^{\prime}=\mathrm{H} \\ \text { in SC } 9420 & R=\mathrm{CH}_{3} ; R^{\prime}=\mathrm{S}-\underset{\mathrm{O}}{\mathrm{C}}-\mathrm{CH}_{3}\end{array}$

Fig. 1.-Chemical structure of the 17 -spirolactosteroids and the cyclohemiacetal form of aldosterone.

Since the isolation of aldosterone by Tait, Simpson and Grundy in $195^{35}$ and its identification in adrenal vein blood ${ }^{29}$ many attempts have been made to establish the place of aldosterone in the regulation of normal electrolyte balance and its importance in the formation of oedema. Methodological problems of estimating the very small amounts of aldosterone in biological fluids are still largely unresolved so that studies of aldosterone metabolism in health and disease remain difficult to interpret. However, in 1957 Cella and Kagawa provided another means of approaching the question. ${ }^{5}$ Encouraged by the studies of Landau and his colleagues 18 which showed an apparent antagonism between sodiumretaining adrenal steroids and progesterone in a patient with Addison's disease, they have developed synthetic steroids which appear to antagonise the effects of mineralocorticoids on the transport of renal tubular sodium and potassium without themselves exerting any detectable effect on urinary electrolyte excretion. Quite a different compound, Amphenone $\mathrm{B}$, is well known to inhibit the production of many adrenal steroids,<smiles>CC12CCC(=O)C=C3CCC4C(CC5(C(C(=O)CO)CCC45)C31)OC2O</smiles>

ALDOSTERONE

(Cyclohemiocetol form) including aldosterone, but its non-specific and widespread effects limit its usefulness in research. ${ }^{13}$ It is too toxic for clinical use but it may increase urinary sodium loss in some patients with oedema. ${ }^{25,34,40}$

These new synthetic steroids are characterised chemically by having a spirolactone grouping attached to the $17^{\text {th }}$ carbon atom of the cyclopentenophenanthrene system which forms the basic steroid nucleus (Fig. I). The spirolactone radical, chosen to mimic the cyclo-hemiacetal group of aldosterone, replaces the $\alpha$-ketol sidechain of the naturally-occurring adrenocortical steroids but the $\triangle^{4}-3$-ketone group in ring $A$ is retained.

The first spirolactosteroid to be elaborated was 3(3 - oxo - I $7 \beta$ - hydroxy - 4 - androsten - $17 \alpha-y l)$ propionic acid $\gamma$-lactone (SC-5233). Kagawa, Cella and Van Arman ${ }^{15}$ showed that both this compound and its 19-nor derivative (SC-8109) modified the ability of aldosterone and deoxycortone to lower the sodium/potassium ratio in the urine of adrenalectomised rats although the compounds were inactive when given alone. A progressive 


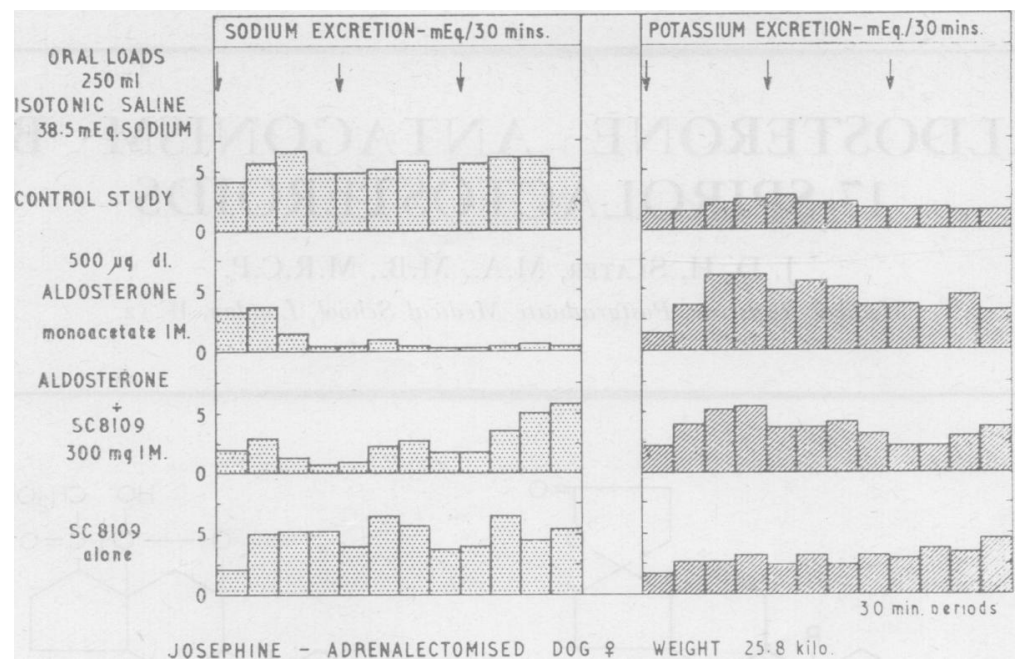

Fig. 2.- Adrenalectomised dog. Effect of dl-aldosterone, a 17-spirolactosteroid (SC-8109) and a combination of the two on the urinary excretion of sodium and potassium. Note the sharp fall in the rate of sodium excretion and the rise of the rate of potassium excretion with aldosterone and its partial inhibition by SC-8109 (from Slater et al., 1959, Lancet, ii, 931).

blocking of the effect was observed with increasing doses. Doubling the amounts at a fixed ratio of spirolactone/deoxycortone did not alter the urine sodium/potassium ratio significantly, suggesting competitive inhibition for receptors on the renal tubule. On a weight for weight basis progesterone, $\mathrm{SC}-5233$ and SC-8109 had relative potencies of I, 7 and 27 respectively. The results with deoxycortone were soon confirmed in adrenalectomised dogs by Liddle ${ }^{20}$ who showed that both the sodium-retaining and the potassium-losing properties of deoxycortone were inhibited. Slater et $a l^{31}$ report similar observations with dl-aldosterone (Fig. 2). More recently a 7 - $\alpha$-thioacetoxy derivative (SC-9420)* has been produced which has similar effects. It appears to be even more potent and is well absorbed from the gastrointestinal tract in contrast to the earlier compounds.

In man, Liddle ${ }^{20,21}$ has performed metabolic studies which support the findings in these animal experiments. Patients with negligible adrenal function due to Addison's disease were maintained on a high sodium intake either alone or combined with 6-methyl prednisolone (a synthetic glucocorticoid with minimal electrolyte effects). By itself SC-5233 was unable to influence the output of sodium or potassium in the urine but when the same patients were given deoxycortone as well, the spirolactone produced a rise in the rate of renal sodium excretion and a slight fall in potassium output. In normal individuals $\mathrm{SC}-5233$ was in-

\footnotetext{
* Trade name 'Aldactone' (G. D. Searle \& Co. Ltd.).
}

effective when aldosterone production was suppressed by a diet rich in sodium, but when the secretion of aldosterone was stimulated by low sodium intake, an increase in the rate of urine sodium output could be obtained. Wiggins and his colleagues $^{39}$ have shown by classical renal clearance techniques that the increased urinary sodium loss is not due to a rise in glomerular filtration rate. In fact, the inulin clearance tended to fall slightly. Liddle also showed that renal hydrogen ion excretion (titratable acid plus ammonia output) falls, contrasting with the rise induced by aldosterone. This has been confirmed by Gantt and Dyniewicz ${ }^{10}$ and by McCrory and Eberlein $^{23}$ using the 19-nor derivative.

By infusing SC-8109 intravenously at a rate of $50 \mathrm{mgm}$. per hour Ross and Bethune ${ }^{26}$ have demonstrated its antagonism to the effects of intravenous $\mathrm{dl}$-aldosterone on urine sodium and potassium excretion in two normal men. These experiments directly confirm that this spirolactosteroid modifies the action of aldosterone. The amounts needed appear to be about I, ooo times as great as the amount of effective aldosterone infused in the racemic form.

In patients with aldosterone-producing tumours of the adrenal, spirolactosteroids will induce sodium loss, potassium retention and a fall of serum bicarbonate concentration in doses of 400 to $2,400 \mathrm{mgm}$. daily ${ }^{17}, 22,27$. Salassa and his colleagues $^{27}$ have further shown that, post-operatively, when the urinary aldosterone excretion of 


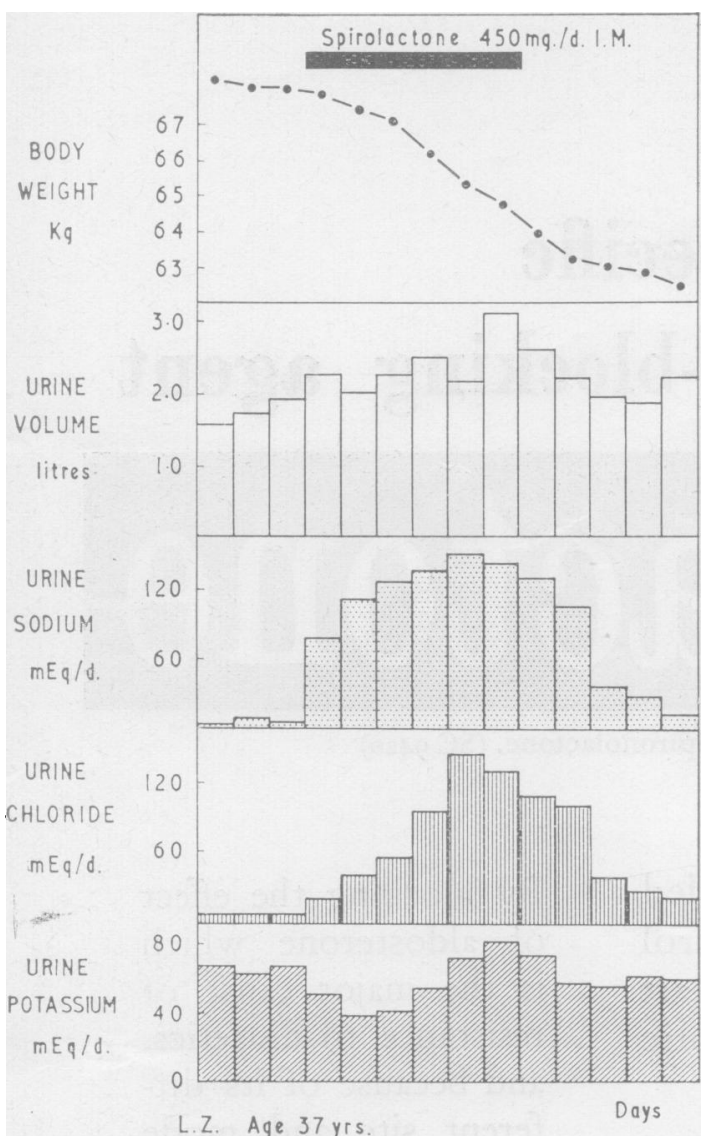

FIG. 3.-Nephrotic syndrome. Effect of a six-day course of SC-8109 on body weight, urine volume and electrolytes. Note the large increase of sodium output, the lesser and delayed rise of chloride excretion and the initial fall of urine potassium loss. Serum potassium rose from 3.3 to $4.4 \mathrm{mEq}$. per litre (from Slater et al., Lancet, ii, 93 I (1959)).

their patient was very low, $\mathrm{SC}-8 \mathrm{r}$ og was no longer effective.

These facts indicate rather strongly that the 17-spirolactosteroids inhibit the effect of aldosterone on electrolyte handling by the renal tubule. The experiments of Conn and his colleagues, ${ }^{6}$ however, suggest that the I9-nor derivative (SC-8ro9) may also possess similar properties which are independent of aldosterone metabolism. An effect analogous to aldosterone antagonism was obtained in two normal men even when the urinary aldosterone excretion was suppressed by a high sodium intake. However, the changes were more marked when aldosterone production was stimulated by dietary sodium restriction. In a patient with primary aldosteronism changes suggesting aldosterone antagonism could be obtained only when sodium was restricted and not when the sodium intake was high although the urinary aldosterone excretion remained unchanged. In animals the effects of hydrocortisone on mineral metabolism can also be antagonised by 17 -spirolactosteroids ${ }^{38}$ so that a close inverse relationship between aldosterone production and spirolactone effect cannot be expected. In any case, antagonism of the small amounts of aldosterone produced when the salt intake is high may allow some sodium loss.

Nevertheless most of the evidence does seem to indicate that, in many circumstances, the 17 -spirolactosteroids behave as if they antagonise the tissue electrolyte effects of both exogenous dlaldosterone monoacetate and naturally-occurring mineralocorticoid hormones. The absence of any action in adrenalectomised subjects would seem to support the thesis that the compounds so far produced do not have any independent action on the renal tubule, although this may not be wholly true of all derivatives.

\section{Other Biological Effects}

Preliminary evidence collected by the manufacturers suggests that 17 -spirolactosteroids are unlikely to have pharmacological effects similar to the adrenocorticosteroids. In small rodents liver glycogen deposition, granuloma formation and the course of virus or bacterial infections are apparently unaffected by any of the three compounds. They do not possess oestrogenic activity, but SC-8Io9 has some progestational effects on the endometrium of immature rabbits in common with other C-2 I, 19-nor steroids.

It is interesting to recall that the cardiac glycosides are also steroidal lactones, digitalis being a steroid with a lactone ring in the 17 -position, and that there is a close structural similarity between the aglycone of digitalis, the 17 -spirolactosteroids and the cyclohemiacetal form of aldosterone. More study, however, is needed to determine whether, like cardiac glycosides and aldosterone, the spirolactosteroids have a direct effect on ion transport across the cell membranes, particularly those of cardiac muscle fibres. In view of the relatively large doses used it is important to know if spirolactosteroids will affect the action of digitalis in patients with a diseased myocardium. Bohr and Cummings ${ }^{2 a}$ report that $\mathrm{SC}-5233$ has a weak DOCA-like action in potentiating contraction of the smooth muscle of rabbit aorta.

\section{Clinical Use of Spirolactosteroids in Oedema}

Most patients who are actively accumulating oedema fluid excrete an almost sodium-free urine which has a high content of aldosterone whether estimated chemically or by biossay.1, 7,41 This suggests, but does not prove, that over-production 
of aldosterone from the adrenal glands may be an important factor in the formation of oedema. Therefore measures which inhibit the peripheral effects of aldosterone should lead to sodium loss and potassium retention, the diuresis being obtained by a physiological mechanism without potassium or excess chloride loss.

In practice this does appear to happen when patients with oedema due to renal or hepatic disease are given adequate amounts of 17 -spirolactosteroids. Fig. 3 illustrates a therapeutically useful diuresis obtained in a man with the nephrotic syndrome when SC-8109 was given intramuscularly in doses of $45^{\circ} \mathrm{mgm}$. daily for six days. Potassium excretion fell slightly and the serum potassium level rose.

Most studies of the clinical effectiveness of spirolactosteroids have been made in cases of cirrhosis of the liver with fluid retention. Bolte and his colleagues ${ }^{3}$ report a good diuresis in two patients when given oral SC-8I09 in doses of 900-I,500 mgm. daily. A similar useful result was obtained by Sleisenger and his co-workers ${ }^{32}$ in patients resistant to other forms of diuretic therapy when either SC-81og was given orally or intra-muscularly or when the oral $7 \alpha$-thioacetoxy derivative (SC-9420) was administered. Kerr and colleagues $^{16}$ and Morrison and Chalmers ${ }^{24}$ had disappointing results with a micro-crystalline suspension of SC-81og by intramuscular injection, but this was an unsatisfactory preparation. In any case, the fluid retention of patients with liver disease is often very difficult to treat, especially when urine sodium excretion is less than I mEq. per day. Such patients may secrete aldosterone at an extremely rapid rate $^{37}$ so that the doses used may have been inadequate. Using the oral SC-9420 (400 mgm. per day) in six patients with ascites, Taylor and Faloon ${ }^{36}$ found that the diuretic response can be greatly improved by giving extra potassium. On a low sodium diet with an intake of $60-80 \mathrm{mEq}$. potassium daily the spirolactone only increased sodium excretion in the urine to a moderate extent. But when the potassium intake was doubled sodium output rose considerably, the serum sodium level falling from $\mathrm{r} 39$ to $132 \mathrm{mEq}$. per litre. Potassium supplements without the spirolactone did not increase renal salt excretion in these patients, although extra potassium will do so in normal individuals, ${ }^{9}$ and, reducing the potassium intake diminished the diuretic effect. This procedure is of great theoretical interest because potassium loading stimulates aldosterone production. ${ }^{19}$ However, there is a danger of inducing hyperkalaemia; in one of Taylor and Faloon's cases the serum potassium concentration rose from 3.6 to $6.0 \mathrm{mEq}$. per litre. ${ }^{36}$

There has been one report of the use of spiro-

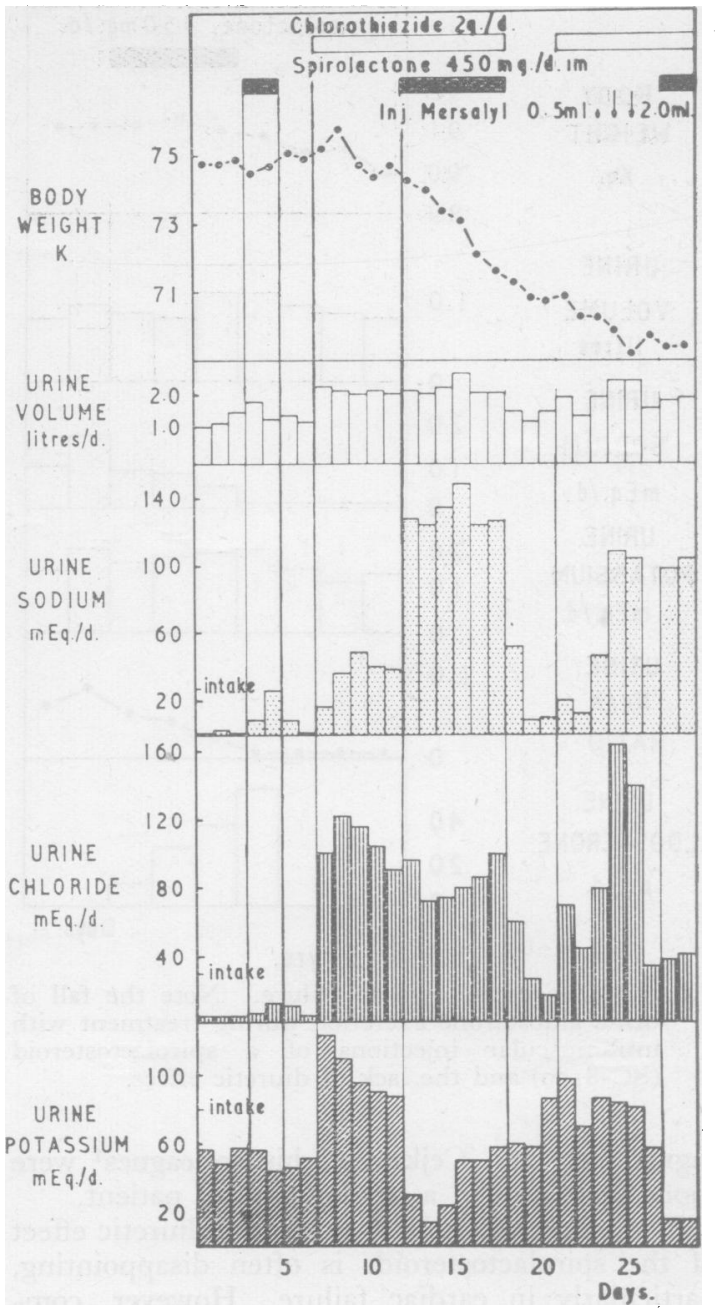

FIG. 4.-Congestive cardiac failure. Effect of a spirolactosteroid (SC-8I09), mersalyl and chlorothiazide on body weight, urine volume and electrolytes. Note the considerable diuresis obtained by combining SC-8ro9 with chlorothiazide when either drug alone was ineffective and the reversal of the potassium-losing action of chlorothiazide (from Slater et al., Lancet, ii, 93 I (1959)).

lactosteroids in pre-eclamptic toxaemia of pregnancy. ${ }^{2}$ Despite the high rate of aldosterone production sometimes seen in normal pregnancy ${ }^{\mathbf{1 4}}$ SC-8rog was ineffective in large oral doses.

In cardiac failure Liddle $^{21}$ has reported that sodium excretion will rise after administration of $\mathrm{SC}-5233$, but in three patients we were unable to produce a useful diuresis in severe chronic heart failure with the more potent SC-8rog in $400 \mathrm{mgm}$. daily doses for six days. ${ }^{31}$ However, by using the oral thioacetoxy derivative in doses of 1,200 


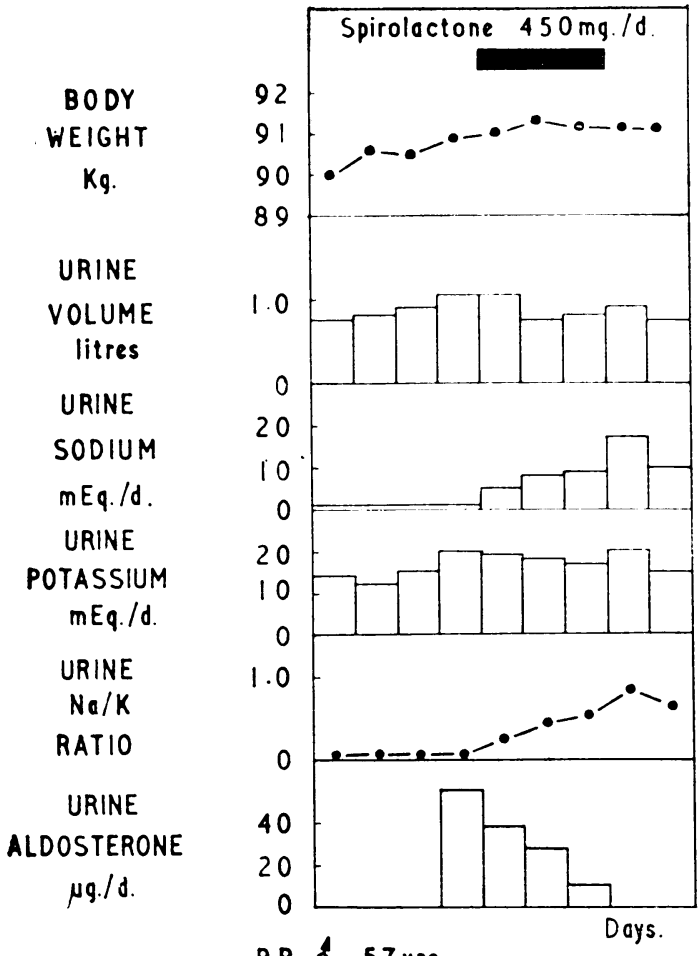

B.B. \& 57 yrs.

FIG. 5.-Congestive cardiac failure. Note the fall of urine aldosterone excretion during treatment with intramuscular injections of a spirolactosteroid (SC-8I09) and the lack of diuretic effect.

mgms. per day, Cejka and his colleagues ${ }^{4}$ were more successful in a similar type of patient.

Therefore, when used alone, the diuretic effect of the spirolactosteroids is often disappointing, particularly in cardiac failure. However, combined with other diuretics (for example, mersalyl or the benzothiazides) a really useful loss of sodium and water may be obtained (Fig. 4). The figure also illustrates the important fact that the potassium-losing action of chlorothiazide can be reversed by giving spirolactones simultaneously. Recently, Kerr et al. ${ }^{16 a}$ have shown that in patients with ascites due to liver damage, the use of SC-9420 combined with chlorothiazide will largely prevent the development of hypokalaemia which otherwise occurs so easily in this type of patient. By the combined use of mannitol infusions, chlorothiazide and SC-9420, many patients with severe ascites who are otherwise resistant to diuretic therapy can be made oedema-free. ${ }^{28}$

These preliminary observations suggest that, considered purely as diuretic agents, the spirolactones, either alone or, more often, in combination with other drugs, may prove useful in the management of patients with severe fluid retention.
They have the advantage over other more potent diuretics that sodium and chloride are lost in proportion to their relative concentrations in the extracellular fluid and potassium excretion remains unchanged or may actually fall.

At first spirolactones are likely to be used only in patients with severe oedema resistant to other forms of diuretic therapy. It is wise to remember that hyperkalaemia may develop if potassium supplements are given and there may be. a fall of the serum sodium concentration.

Further studies are needed to determine the detailed indications and optimal doses required. At present it seems that in daily amounts of 400 to $1,200 \mathrm{mgm}$., the oral $7-\alpha$-thioacetoxy derivative (SC-9420) will increase the urinary sodium output in the majority of oedematous patients providing they are not uraemic. There appears to be considerable variation in the speed of action, but a diuresis may take 2-3 days to develop and a corresponding period to diminish when the drug is stopped. Metabolic studies and therapeutic expectations, therefore, must be adjusted accordingly.

Spirolactosteroids appear to be virtually nontoxic in experimental animals. However, humans may experience drowsiness in large doses $(2 \mathrm{gm}$. or more daily) and sensitivity reactions have occurred with the oral thioacetoxy compound.

\section{Steroid Metabolism During Treatment with Spirolactosteroids}

If, as seems likely, the spirolactosteroids act mainly by antagonising the peripheral effects of aldosterone, then other factors remaining unchanged, the production-rate of the hormone should rise. Liddle ${ }^{21}$ found either a rise or no change in the urine aldosterone output of normal men and a patient with the nephrotic syndrome. Bolte and his colleagues ${ }^{3}$ found a considerable rise of urine aldosterone excretion in a patient with cirrhosis of the liver given SC-8ro9. Slater, Moxham, Hurter, and Nabarro ${ }^{31}$ measured the secretion-rate in two of their patients with oedema by giving tritium-labelled aldosterone and estimating the specific activity of the urinary aldosterone after extraction at $p \mathrm{Hr}$. In one man the value rose from 353 to 695 microgrammes daily and in the other there was no change, despite a net loss of nearly $1,000 \mathrm{mEq}$. of sodium and $7.7 . \mathrm{kg}$. in body-weight over 6-7 days.

The urinary excretion of total i 7 -hydroxycorticosteroids and 17 -ketosteroids does not seem to alter during treatment with moderate doses of spirolactosteroids. ${ }^{6,31,20}$ One group of workers reported a decrease in conjugated urinary $17-$ hydroxycorticosteroids, ${ }^{3}$ but this was apparently due to a fall in renal clearance. After giving the $7 \alpha$-thioacetoxy derivative (SC-9420), the urine 
may contain material which gives a dark brown colour (maximum absorbance at $4 \mathrm{I} 5 \mu$ ) with Zimmerman reagent. This will interfere with determinations involving this reaction (e.g. I7ketosteroid estimations) unless suitable corrections are made. None of the spirolactosteroids interfere with the usual chromatographic techniques for the isolation of aldosterone.

Thus there is no evidence that the compounds affect adrenocortical function directly. However, in oedematous states there are so many factors which could influence adrenocortical activity during diuretic therapy (particularly aldosterone production) that changes of steroid excretion are difficult to interpret. Most patients who lose oedema during successful treatment of the underlying disorder show a fall in urinary aldosterone output, ${ }^{7,42}$ whereas aldosterone production might otherwise be expected to rise owing to sodium loss and contraction of the extracellular fluid space. It is therefore perhaps rather surprising that in two patients who showed virtually no response to SC-81o9, Slater et al. ${ }^{31}$ observed a definite and progressive fall in urinary aldosterone excretion (Fig. 5). This remains unconfirmed, but assuming that spirolactosteroids have no effect on the adrenal glands directly, it suggests indirect adrenal inhibition, possibly via the hypothalamic controlling centre. ${ }^{8}$

The relationship between the diuretic response and aldosterone metabolism in patients with oedema has yet to be clearly defined. If the main action of the I7-spirolactosteroids in patients with fluid retention is to antagonise the tissue effects of an inappropriately high rate of aldosterone production, then the diuretic response should be related to it. Preliminary evidence does not support this idea, however. In two patients with oedema we found that SC-8109 produced an increase in urine sodium output (one man lost nearly $\mathrm{I}, 000 \mathrm{mEq}$. in 7 days) although the aldosterone secretion-rate was within the normal range despite dietary salt restriction. Conversely, little response was obtained in two other patients who were excreting large quantities of aldosterone in the urine, although in one case the aldosterone output fell progressively to within normal limits during spirolactone therapy. These results imply either that the spirolactosteroids have a diuretic effect which is independent of aldosterone metabolism (by antagonising some other mineralocorticoid hormone, for example), or that hyperaldosteronism is not an important factor in the formation of oedema fluid.

Hypertension. In common with other diuretics, particularly benzothiazides, the spirolactosteroids will tend to lower the blood pressure in patients with arterial hypertension if increased salt loss occurs. Whether there is some blood pressurelowering effect which is not related to a fall in plasma volume is unknown at present, but it is interesting that one group of workers ${ }^{11,12}$ consider that aldosterone production is abnormally high in severe essential hypertension. Sturtevant ${ }^{33}$ has shown that in rats SC-5233 prevents the development of hypertension after enucleation of the adrenals, ${ }^{30}$ without inhibiting regeneration of the glands. After removing the offending tumour in Conn's syndrome, the elevated blood pressure falls at first but often returns some months later. In the case described by Salassa and his folleagues ${ }^{27}$ there was no drop of blood pressure preoperatively, despite giving large doses of SC-8 rog for I 9 days. Nevertheless the spirolactosteroids may have a place in the long-term treatment of arterial hypertension when combined with ganglion-blocking drugs (or those which paralyse the adrenergic neurones) because unlike the benzothiazides, there is no tendency to potassium loss.

In conclusion, the 17 -spirolactosteroids seem to have the unique property of promoting potassium retention at the same time as increasing sodium loss in the urine. The information at present available suggests that, as predicted from their structural formula, they do this by antagonising the peripheral effects of mineralocortical hormones. These compounds may, therefore, help to elucidate the role of the adrenal glands in many conditions, particularly fluid retention. Therapeutically the diuretic effect is usually a weak one in the doses at present used, but when combined with other drugs a really useful loss of oedema fluid can be obtained without the dangers of potassium depletion.

\section{REFERENCES}

r. AXELRAD, B. J., CATES, J. E., JOHNSON, B. B., and LUETSCHER, J. A. (1955) Brit. med. f., i, 196.

2. BARNES, A. C., and BUCKINGHAM, J. C. (1958), Amer.

2a. BOHR, D. F., and CUMMINGS, G. (1958), Fed. Proc.,

3. BOLTE, E., VERDY, M., MARC-AURELE, J., BROUILLET, J., BEAUREGARDE, P., and GENEST, J. (1958), Canad. med. Ass. F., 79, 881.

4. CEJKA, V., DE VRIES, L. A., and BORST, J. G. G. (1960), Lancet, $1,312$.

5. CELLA, J. A., and KAGAWA, C. M. (1957), F. Amer. chem.

6. CONN, J. W., LOOUIS, L. H. FAJANS, S. S., STREETAN, D. H. P.' JOHNSON, R. D., MOORHOUSE, J. R., CRANE, M. G., BERKER, A.

7. DUNCAN, L. E., JR., LIDDLE, G. W., and BARTTER, F.C. (1956), $\mathcal{F}$. clin. Invest., 35, 1299.

8. FARRELL, G. (I958), Physiol. Rev., 38, 709.

9. GAMBLE, J. L. (1953), Pediatrics, i1, 554 .
Io. GANTT, C. L., and DYNIEWICZ, J. (1959), Clin. Res. Proc.,

I1. GENEST. Y., LEMIEUX, G., DAVIGNON, A., KOIW, E., NOWACZYNSKI, W., and STEYERMẢRK, P. (1956), Science, 123, 503

12. GENEST, J., KOIW, E., NOWACZYNSKI, W., and LEBOEF, 'G. (I958), Clin. Res. Proc, 6, 28.

13. HERTZ, R., PITTMAN, J. A., and GRAFF, M. M. (1956), F. clin. Endocr., 16, 705.

References continued on Page 407 


\section{BIOCHEMICAL ASPECTS OF NEUROLOGICAL DISORDERS}

Edited by J. N. Cumings and M. KREMer. Pp. 230. Blackwell Scientific Publications, Oxford. 1960. 37s. $6 \mathrm{~d}$.

In this book an attempt has been made to cover all apsects of neurological disease known to be associated with biochemical dysfunction. The articles, which are written by experts in the field, are mostly paired, the first of the pair discussing biochemical and pathological aspects of the disease, and the second dealing with the same condition from a more clinical point of view. Sometimes the connection with biochemistry seems rather tenuous, and in the second chapter on B vitamins too much space seems to be given to pernicious anaemia in its non-neurological aspects, though the historical summary of this subject is most interesting. There are excellent chapters on porphyrins (it is a pity that no references are given to these), and on biochemical disorders of muscle.

Neurological biochemistry is a rapidly expanding subject, with great future possibilities. This book provides a useful and interesting review of the present state of knowledge in the field, and relates the biochemical findings to clinical syndromes.

\section{TREATMENT OF CANCER AND ALLIED DISEASES}

\section{Vol. III. Tumours of the Head and Neck}

Edited by George T. Pack, M.D., F.A.C.S., and Irving M. Ariel, M.D., F.A.C.S. Second edition. Pp. 781 + xviii, with 1,028 illustrations. London: Pitman Medical Publishing Co. Ltd. 1959. fiI I Is.

The third volume of this nine-volume work is devoted to the treatment of malignant tumours of the head and neck, but includes a wide survey of the relevant anatomy and pathology and for some regions gives an interesting historical account of the development of treatment. The general principles of treatment of anaesthesia and of pre- and postoperative care are fully discussed. Individual regions are dealt with in great detail by 70 different authors drawn from an international field, and a careful balance struck between surgery and radiotherapy and stress laid on combined methods of treatment.

The whole volume is beautifully produced, contains a wealth of excellent illustrations, photographs and diagrams and includes an extensive bibliography and a very adequate index.

References continued from Page 405. F. D. H. Slater, M.A., M.B., M.R.C.P.

14. JONES, K. M., LLOYD-JONES, R., RIONDEL, A., TAIT, J. F., TAIT, S. A. S., BULBROOK. R. D., and GREENWOÖD, F. C. (1959), Acta endocr. (Kbh.).

15. KAGAWA, C. M., CELLA, J. A., an I VAN ARMAN, G. C. (1957,) Science, 126, IOI 5 .

I6. KERR, D. N. S., READ, A. E., HASLAM, R. M., and SHERLOCK, S. (I958), Lancet, ii, ro84.

16a. KERR, D. N. S., READ, A. E., HASLAM, R. M., and SHERLOCK, S. (1960), Personal communication.

17. KISTLER, H., SHELLEY, T. F., and FRAWLEY, T. F. (1959), Clin. Res. Proc., 7, 254.

18. LANDAU, R. L., BERGENSTAL, D. M., LUGIBIHL, K., and KASCHT, M. E. (1955), Ұ. clin. Endocr., 15, I 194.

19. LARAGH, J. H. and STOERK, H. C. (1957), F. clin. Invest., 36, 383 .

20. LIDDLE, G. W. (1957), Science, 126, 1016.

21. LIDDLE, G. W. (1958), Archl intern. Med., 102, 998.

22. LUETSCHER, J. A., Jr. (1958), Arch. intern. Med., 102, 3 I4.

23. MCCRORY, W. W., and EBERLEIN, W. R. (1958), F. clin. Invest., 37, 917.

24. MORRISON, R. S., and CHALMERS, T. C. (1958), Clin. Res. Proc., 6, 300 .

25. RENOLD, A. E., CRABBE, J., HERNANDO-AVENDANO, L., NELSON, D. H., ROSS, E. J., EMERSON, K., JR., and THORN, G. W. (1957), New Engl. F. Med., 256, i6.

26. ROSS, E. J., and BETHUNE, J. E. (1959), Lancet, i, 127.

27. SALASSA, R. M., MATTOX, V. R., and POWER, M. H. (1958), भ̆. clin. Ëndocr., 18, 787.

28. SHALDON, S., MCLAREN, J. R., and SHERLOCK, S. (1960), Lancet, i, 609 .
29. SIMPSON, S. A., TAIT, J. F., and BUSH, I. E. (r952), Lancet, ii, 226.

3o. SKELTON, F. R. (1959), Physiol. Rev., 39, I62.

31. SLATER, J. D. H., MOXHAM, A., HUR'TER, R., and NABARRO, J. D. N. (1959), Lancet, ii, 93 I.

32. SLEISENGER, M. H., RICHARD, J. O., KOWLESSAR, D., CLARKSON, B., THOMPSON, D., and PETERSON, R. E. (1959), Clin. Res. Proc., 7, 37.

33. STURTEVANT, F. M. (I959), Endocrinology, 64, 299.

34. SUMMERSKILL, W. H. J., and CRABBE, J. (I957), Lancet, ii, 1091 .

35. TAI'T, J. F., SIMPSON, S. A., and GRUNDY, H. M. (I952), Ibid., $\mathbf{i}, \mathbf{1} 22$.

36. TAYLOR, F. F., and FALOON, II. W. (1 959), 7. clin. Endocr., 19, 1683 .

37. ULICK, S., LARAGH, J. H., and LIEBERMAN, S. (I958), Trans. Ass. Amer. Physns., 71, 225.

38. VENNING, G. R. (I960), personal communication.

39. WIGGINS, R. A., HUTCHIN, M. E., CARBONE, J. V., and DOOLAN, P. D. ( 1 959), Proc. Soc. Exper. Biol. \& Med., 100, 625 .

40. WOLFE, S. J., FAST, B., STORMONT, J. M., and DAVIDSON, C. S.'(1957), New Engl. F. Med., 257, 2 I 5.

4r. WOLFF, H. P., KOCZOREK, K. R., and BUCHBORN, E. (I957), Lancet, ii, 63 .

42. WOLFF, H. P., KOCZOREK, K. R., and BUCHBORN, E. (1958) 'International Symposium on Aldosterone,' p. I93. J. \& A. Churchill Ltd. 